A. Н. Плеханов. Диапевтика острых хирургических заболеваний органов брюшной полости в подготовке начинающих врачей-хирургов

УДК 617-089:616.381

DOI: 10.18101/2306-1995-2019-1-3-6

\title{
ДИАПЕВТИКА ОСТРЫХ ХИРУРГИЧЕСКИХ ЗАБОЛЕВАНИЙ ОРГАНОВ БРЮШНОЙ ПОЛОСТИ В ПОДГОТОВКЕ НАЧИНАЮЩИХ ВРАЧЕЙ-ХИРУРГОВ
}

\author{
(C) Плеханов Александр Николаевич \\ доктор медицинских наук, профессор, \\ заведующий кафедрой факультетской хирургии, Медицинский институт, \\ Бурятский государственный университет имени Доржи Банзарова, \\ ведущий научный сотрудник, \\ Иркутский научный центр хирургии и травматологии \\ Россия, 670001, г. Улан-Удэ, ул. Комсомольская, 16 \\ тел/факс: 8 (3012) 28-35-03 \\ E-mail: plehanov.a@mail.ru
}

В данной статье автором раскрыты основополагающие принципы ранней диагностики острых хирургических заболеваний живота, как профилактику развития серьезных жизнеугрожающих осложнений. Так показано, что позднее обращение за медицинской помощью, а также диагностические ошибки приводят к запоздалой госпитализации со всеми вытекающими из этого последствиями. Особое внимание уделяется вопросам диспансеризации. Цель ее - профилактика острых хирургических заболеваний, а не их ранняя диагностика. Одним из направлений по ранней диагностике острых хирургических заболеваний является санитарнопросветительная работа. Улучшение ранней диагностики острой хирургической патологии немыслимо без внедрения в практику современных малоинвазивных диагностических и лечебных технологий. Принципы ранней диагностики острой хирургической патологии органов брюшной полости в комплексе позволяют улучшить качество оказания медицинской помощи больным.

Ключевые слова: острые хирургические заболевания живота, ранняя диагностика, осложнения, результаты.

Для цитирования:

Плеханов А. Н. Диапевтика острых хирургических заболеваний органов брюшной полости в подготовке начинающих врачей-хирургов // Вестник Бурятского государственного университета. Медицина и фармация. 2019. Вып. 1. С. 3-6.

Одним из основных принципов экстренной хирургии, оказывающих существенное влияние на результаты лечения больных, является ранняя диагностика острых хирургических заболеваний органов брюшной полости (ОХЗОБП) [1]. Практика показывает, что именно здесь наши коллеги допускают наибольшее количество диагностических ошибок. Некоторые врачи нередко формально без достаточного критического анализа подходят к тем мероприятиям, которые необходимы для точной диагностики ОХЗОБП, что ухудшает отдельные показатели, характеризующие организацию медицинской помощи этой категории больных. Основная работа в этой проблеме принадлежит амбулаторнополиклиническому звену. Совершенно очевидно, что результаты лечения больных, например, с язвенной болезнью желудка и двенадцатиперстной кишки значительно хуже при развитии таких грозных осложнений этой патологии, как кро- 
вотечение, перфорация, малигнизация. Наиболее раннее выявление болезни позволяет избежать этих осложнений.

Нередко с диагнозом «острый живот» пациент впервые обращается не к хирургу, а к врачу другой специальности (терапевту, педиатру, анестезиологу, стоматологу и другим). Упущения этих врачей, своевременно не разобравшихся в правильности диагноза, далеко не редки. Тем не менее, в первую очередь врачхирург является ответственным за поступление больных с острой хирургической патологией в стационар в поздней стадии заболевания. Поздняя госпитализация обусловлена, прежде всего, двумя основными причинами: 1) поздняя обращаемость пациента и 2) диагностические ошибки медицинских работников на догоспитальном этапе.

Важным моментом в ранней диагностике ОХЗОБП является диспансеризация населения и направление больных для планового оздоровления. Цель диспансерного наблюдения профилактика острых хирургических заболеваний, а не их ранняя диагностика. Система диспансерного наблюдения, применяемая нами, включает: оперативное лечение хронической хирургической патологии, наблюдение за оперированными больными, наблюдение за больными с повышенным хирургическим риском отказывающихся от выполнения операций в плановом порядке. Проведение диспансеризации населения преимущественно направлено на оказание практической помощи участковым врачам и районным специалистам в проведении комплексных осмотров населения, выявление заболеваний в ранних стадиях их развития, и в конечном итоге - на улучшение качества лечения.

В последние годы особое значение для диагностики ОХЗОБП имеет метод гипердиагностики, т. е. определение излишне широких границ установления диагноза того или иного хирургического заболевания (например, перфоративной язвы при язвенной болезни, острого панкреатита у больного гастритом, острой непроходимости кишечника при спаечной болезни или спастическом колите и др.). В связи с этим связанная с гипердиагностикой «излишняя» загруженность хирургов стационаров обследованием больных, не имеющих якобы отношения к острой хирургической патологии, не может быть оправдана, так как речь в первую очередь идет об органзационно-тактическом принципе - выполнение операции в ранние сроки заболевания.

Абсолютна, неприемлема формулировка диагноза хирурга, после осмотра больного - «хирургических заболеваний нет» или «острая хирургическая патология отсутствует». А между тем в диагноз острого хирургического заболевания исключается у 21-34\% больных с неотложными состояниями. Думаем правильным должно быть стремлением врача установить правильный диагноз, с применением всех современных диагностических методов, а не исключить хирургический. Это уровень современного квалифицированного, думающего врача.

Принципиально важное значение в раннем выявлении острой хирургической патологии имеет коллегиальный осмотр больного с привлечением специалистов смежных с хирургией специальностей. Здесь огромная польза будет и врачухирургу и всем другим врачам, осматривавшим больного, а самое главное - и самому этому больному. Как говорится: «одна голова хорошо, а две лучше». С другой стороны — врач, осматривавший с хирургом пациента, приобретает знания и навык в диагностике «острого живота». Кроме того принципиально важным считаем привлечение к осмотру, наиболее опытных врачейспециалистов, а также профессорский состав кафедральной клиники. 
Одним из направлений по ранней диагностике ОХЗОБП является санитарнопросветительная работа, которая играет основное значение в снижении частоты поздней обращаемости больных и случаев самолечения. Безусловно, в проводимых лекциях излагается этиология, ведущие симптомы и осложнения острых хирургических заболеваний, подчеркивается их опасность и необходимость немедленного обращения к врачу, которое, к сожалению, наблюдается далеко не всегда. Но самое главное надо приучить слушателя думать о своем здоровье, заботься о нем. Так, повышение эффективности оказания помощи больным с острой непроходимостью кишечника, на фоне обтурирующей опухоли кишки, заключается в наиболее ранней диагностике опухоли, еще до развития осложнения-клиники острой кишечной непроходимости. В связи с этим каждый должен знать первые признаки этой болезни (частые запоры, потеря веса тела, снижение аппетита и другие).

Улучшение ранней диагностики острой хирургической патологии немыслимо без внедрения в практику современных малоинвазивных диагностических и лечебных технологий, стремительно меняющих лицо хирургии. В категорию рутинных методов диагностики уходят стандартные рентгенологические, эндоскопические, ультразвуковые исследования. Им на смену пришли компьютерные томографические методы, ангиографические, которые являются «золотым» стандартом в диагностике поражения сосудов. Появление эндоскопического ультразвукового исследования позволило соединить ценность двух методик, позволяющее с высокой степенью достоверности определить интрамуральную распространенность опухолевого процесса и наличие метастатических изменений лимфоузлов. Все эти методы позволили усовершенствовать технологию выполнения многих операций [2].

Таким образом, указанные принципы ранней диагностики острой хирургической патологии органов брюшной полости в комплексе позволяют улучшить качество оказания медицинской помощи больным. Это, прежде всего, проведение тотальной диспансеризации населения, внедрение новых лечебных и диагностических медицинских технологии в практику, повышение уровня квалификации врачебных кадров и санитарно-просветительная работа с населением.

\section{Литература}

1. Павловский М. П., Фильц О. В., Рачкевич С. Л. Резервы улучшения ранней диагностики острых хирургических заболеваний органов брюшной полости на догоспитальном этапе // Клин. хирургия. 1989. № 4. С. 50-52.

2. Савельев В. С. Хирургия на рубеже тысячелетий // Русский медицинский журнал. 2002. T. 10, № 26. С. 1200-1203.

\section{DIAPEUTICSIN CASES OF ACUTE SURGICAL DISEASES \\ OF THE ABDOMINAL CAVITY IN THE TRAINING PROCESS OF NEW SURGEONS}

\section{Aleksandr N. Plekhanov}

Doctor of Medical Sciences, Professor,

Head of the Department of Intermediate Level Surgery,

Medical Institute, Dorzhi Banzarov Buryat State University

36a, Oktyabrskaya st, Ulan-Ude, 670001, Russia

Leading Research Officer 
Irkutsk Scientific Center of Surgery and Traumatology

Tel./fax: +7(3012) 28-35-03

E-mail: plehanov.a@mail.ru

In this article, the author reveals the basic principles of early diagnosis of acute surgical diseases of the abdomen, as the prevention of serious life-threatening complications. So it is shown that the late request for medical help, as well as diagnostic errors lead to late hospitalization with all the ensuing consequences. Special attention is paid to the clinical examination. Its goal is the prevention of acute surgical diseases, not their early diagnosis. One of the directions for the early diagnosis of acute surgical diseases is sanitary and educational work. Improving the early diagnosis of acute surgical pathology is unthinkable without the introduction of modern minimally invasive diagnostic and therapeutic technologies. The principles of early diagnosis of acute surgical pathology of the abdominal organs in the complex can improve the quality of medical care to patients.

Keywords: acute surgical diseases of the abdomen, early diagnosis, complications, results. 